\title{
QUE TIPO DE SABER É O DIREITO? ENTRE A CIÊNCIA, A PRUDÊNCIA E A TÉCNICA
}

\author{
WHAT KIND OF KNOWLEDGE THE LAW IS? AMONG SCIENCE, \\ PRUDENCE AND TECHNIQUE
}

\author{
Renato José de Moraes \\ Universidade Federal do Rio de Janeiro (Rio de Janeiro, RJ, Brasil)
}

Recebimento: 27 jun. 2016

Aceitação: 17 fev. 2017

\begin{abstract}
Como citar este artigo / How to cite this article (informe a data atual de acesso / inform the current date of access):
\end{abstract}
MORAES, Renato José de. Que tipo de saber é o direito? Entre a ciência, a prudência e a técnica. Revista da Faculdade de Direito UFPR, Curitiba, PR, Brasil, v. 62, n. 1, jan./abr. 2017, p. 83 - 111. ISSN 2236-7284. Disponível em: <http://revistas.ufpr.br/direito/article/view/47451>. Acesso em: 30 abr. 2017. DOI: http://dx.doi.org/10.5380/rfdufpr.v62i1.47451.

\begin{abstract}
RESUMO
A filosofia aristotélica divide os saberes, ou virtudes intelectuais, em cinco classes: as ciências, a sabedoria, a inteligência, as técnicas e a prudência. Neste artigo, busca-se explicar esses tipos de saberes e verificar em qual deles o direito seria mais bem classificado. A importância de tal estudo é que cada uma das virtudes intelectuais detém características próprias, que determinam a maneira de adquiri-las e desenvolvê-las, bem como quais são suas finalidades. Por isso, o modo como tratamos o direito depende diretamente de como definimos o seu estatuto epistemológico. A ciência e a sabedoria são virtudes intelectuais teóricas, com pretensões a alcançar o universal e necessário, enquanto a técnica e a prudência são práticas, voltadas para o individual e contingente. A prudência abrange as ações humanas responsáveis, influenciadas pelos apetites do agente, enquanto a técnica diz respeito ao produto de um fazer. Nesse quadro, o direito encaixa-se principalmente como uma técnica ou arte, pois seu objeto é a realidade humana concreta, com sua precariedade e contingência. Tal foi o entendimento dos juristas romanos e medievais, e segue defensável nos dias de hoje.
\end{abstract}

\section{PALAVRAS-CHAVE}

Aristóteles. Epistemologia. Técnica jurídica. Ciência.

\begin{abstract}
Aristotle's Philosophy divides the kinds of knowledge in five intellectual virtues: sciences, wisdom, intelligence, technique and prudence. This article intends to explain these classes of virtues and in which of them the law can be rightly classified. This classification is important because each intellectual virtue has its particular characteristics, which determine the way they can be acquired and developed, as well as their finalities. In fact, the way we deal with the law depends directly on how we define its epistemological class. Science and wisdom are theoretical intellectual virtues that search the universal and the necessary, while technique and prudence are practical, directed to the individual and the contingent. Prudence is related to conscious human actions, which are influenced by the appetites of the agent, while technique is related to a product to be done outside the agent. All things considered, law is primarily a technique or an art, because its immediate object is the human reality,
\end{abstract}


with its precariousness and contingency. That is how the Roman and medieval jurists understood law, and this position is still tenable.

\section{KEYWORDS}

Aristotle. Epistemology. Judicial technique. Science.

\section{INTRODUÇÃO}

O direito é um saber. Ao menos, essa é uma das suas acepções legítimas e consagradas, que está por trás de expressões como ciência do direito, jurisprudência e arte jurídica. Ninguém duvida de que o direito implique um arcabouço de conhecimentos. Ao mesmo tempo, as características desses conhecimentos jurídicos, bem como suas finalidades - se propriamente servem para algo... -, são questões controversas, cujas respostas variam ao sabor das distintas correntes da filosofia, sociologia e antropologia.

Com fundamento em Aristóteles, cabe considerar os saberes em geral a partir de dois pontos de vista. Do lado do sujeito, de quem os possui, são virtudes intelectuais. Ou seja, hábitos que aperfeiçoam o uso da razão. A noção de hábito indica algo que se possui, não simplesmente como um costume ou condicionamento, e sim como uma disposição pela qual algo ou alguém está bem ou maldisposto, seja em si mesmo, seja em relação a outra coisa (ARISTÓTELES, Met., l. V, c. 20: 1022, b, 10-12). Os hábitos desenvolvem as capacidades que possuímos, aperfeiçoando-as ou, pelo contrário, enfraquecem-nas, podendo inclusive esterilizá-la (ABBÀ, 1995, p. 174-175). Daí que certos hábitos são denominados virtudes, e outros, vícios.

No caso dos hábitos intelectuais, eles são vários tipos de disposições para conhecer, conforme será examinado adiante. Adquirimos tais hábitos por meio do estudo, da demonstração, do treino e da argumentação, de maneira que cheguemos a obter uma noção completa de determinado campo, a dominá-lo com maestria. Passam então a ser qualidades estáveis do sujeito, que dificilmente se perdem (TOMÁS DE AQUINO, S.T., İ-IIae q. 51 a. 2 со.)

Do outro ponto de vista, os saberes são analisados em relação ao seu conteúdo, isto é, de forma objetiva. Formam então um conjunto de conhecimentos, mais ou menos coordenado ou sistematizado, de acordo com o que permita a sua matéria. São noções, premissas, desenvolvimentos, inferências e conclusões, que aos poucos vão sendo apropriados pelos que os estudam. Quando essa apropriação por parte do sujeito torna-se considerável, o conhecimento objetivo serve de fundamento, matéria de uma virtude intelectual (ARISTÓTELES, Ethic., l. 6, c. 2; 1139, b, 12 - 13).

Portanto, na medida em que esses conhecimentos objetivos são obtidos pelo sujeito, criam- 
se nele hábitos, ou seja, disposições em relação àquele saber objetivo. O sujeito tem dentro de si o conhecimento, as diversas virtudes intelectuais - como a tradição aristotélica as denomina - que aperfeiçoam a mente, a razão do indivíduo, expandindo-a e tornando-a capaz de realizações que antes lhe estavam vedadas (TOMÁS DE AQUINO, S.T., I I-II ${ }^{\text {ae }}$ q. 57 a. 1 e 2). Adquire então o domínio sobre uma área do saber, que poderá ser mais ou menos amplo.

Por exemplo, ao aprender uma determinada língua, o agente fica apto a entendê-la, a fazer uso dela, o que não era o caso antes de conhecê-la com a necessária profundidade e amplitude. Se adquirir, a respeito dessa língua, uma cognição que chegue à estrutura, às regras da mesma, alcança então um patamar superior ao do mero uso ou do saber prático. É o que se dá com o gramático, por exemplo, que possui o hábito da ciência - a gramática - sobre um objeto que consiste em um conjunto de conhecimentos a respeito de um aspecto da realidade, que, no caso, é a própria língua. Essa mesma relação entre hábito e objeto é a que encontramos em quem conhece profundamente a química, a física ou o esculpir: algo no sujeito, relativo a um conjunto de conhecimentos que lhe são externos e objetivos (BROADIE, 1991, p. 187-188).

Neste trabalho, procuraremos responder à pergunta: dentre as categorias dos saberes propostas por Aristóteles, à qual corresponde o direito? Apresenta-se como uma questão importante, pois da resposta a ela dependem o método, a finalidade e o grau de certeza relacionados ao estudo do direito. Afinal, objetos de conhecimento distintos correspondem a diferentes hábitos intelectuais, cada um com características próprias, segundo analisaremos abaixo.

O recurso a Aristóteles justifica-se pela relevância, que cresceu de modo especial nas últimas décadas, que esse autor possui em todo âmbito da filosofia prática. Escolas influentes nos dias de hoje, como a nova retórica de Perelman ou a tópica de Viehweg, são de certo modo herdeiras de Aristóteles (BERTI, 1997, p. 229-299). Portanto, apesar de em certos aspectos alguns considerarem o pensamento aristotélico ultrapassado, a maior parte das suas afirmações continuam sugestivas e enriquecedoras, conforme pretendemos demonstrar.

Estudaremos inicialmente as principais espécies de saberes, tanto especulativos quanto práticos. Apesar de isso não nos levar diretamente a temas jurídicos, é uma introdução necessária para que compreendamos os conceitos aristotélicos, a partir dos quais tentaremos raciocinar a respeito do direito. Posteriormente, procuraremos indicar em qual das categorias de virtudes intelectuais, identificadas por Aristóteles, o direito se encaixaria melhor. 


\section{O QUADRO DAS VIRTUDES INTELECTUAIS}

O ser humano pode adquirir e desenvolver qualidades que lhe permitam realizar ações e obras mais perfeitamente. Tais qualidades aperfeiçoam alguma potência ou faculdade humana. As potências são características, tipos de qualidades que fazem com que o ser humano seja como é: capaz de conhecer, pensar, sentir, querer, mover-se, crescer, alimentar-se, procriar, etc. São princípios de ação e de movimento, estreitamente ligados à essência do sujeito, pois frequentemente auxiliam para a caracterização de cada ente. Como a ação de um determinado sujeito segue o seu modo de ser, por meio da ação das potências, distinguimos os vários tipos de entes (ARISTÓTELES, Cat., 8; 9, a, 14 $-16)$.

As potências podem ou não estar agindo, sem que isso modifique a essência do indivíduo. Como o próprio nome delas dá a entender, elas possibilitam a ação, ainda que não a realizem necessariamente: são potências e não garantem que haja atualidade imediata e presente, isto é, a ação. Exercer ou não a inteligência, querer ou não algo, dependem da utilização das próprias potências; sem a presença da potência, nem sequer caberia pensar em um posterior ato. Contudo, para se exercitar uma ação, não é suficiente existir a potência, porque esta necessita ser atualizada pelo sujeito.

Dentre as faculdades do ser humano, algumas são dominadas pelo próprio agente, e por isso as ações que surgem delas são livres, controladas e responsáveis. Outras faculdades são ao menos em parte subjugadas pela racionalidade e pela vontade, e por isso seu emprego também cai sob a responsabilidade do agente. As faculdades em que há um grau efetivo de liberdade são exatamente a razão e os apetites, incluindo nestes últimos a vontade e os sentimentos. Por participarem, cada uma em certa medida, da razão, todas essas faculdades são humanas e distintas das que encontramos em outros seres animados. Os animais possuem sentimentos, mas não têm uma razão para controlá-los, o que modifica bastante toda a dinâmica da sua sensibilidade em relação à do ser humano (TOMÁS DE AQUINO, S. T., I' q. 81 a. 3 co.; I'-IIae q. 6 a. 1 co.).

Há também faculdades que estão fora do alcance consciente do sujeito, no sentido de que não pode controlá-las, e por isso não são potências livres. Em outras palavras, elas exercem seu movimento de forma independente à vontade do indivíduo. É o que se dá com o crescimento, com a nutrição, com a procriação. Evidentemente, a ação de comer é livre; porém, o processo pelo qual são sujeitos os alimentos no interior do corpo do ser vivo, com a digestão, dá-se por si mesmo, sem o controle da vontade e da inteligência. O mesmo vale para a reprodução e para o crescimento, no seu desenvolvimento no sujeito (ARISTÓTELES, De Anima, l. 2, c. 4; 415, a, 23 - b, 8; TOMÁS DE 
AQUINO, S. T., I ${ }^{\text {a }}$ q. 78 a. 1 co.).

A liberdade das potências implica multiplicidade de possibilidades; ou seja, uma potência que não está determinada a algo pode dirigir-se a diferentes pontos ou metas. A vontade pode aceitar ou negar, com velocidade ou com lentidão; a inteligência pode ou não conhecer algo que lhe é mostrado, dependendo da sua configuração; o sujeito pode sentir medo ou ímpeto diante de um obstáculo, e assim por diante.

Em seu estado puro, as potências apresentam dificuldade para agir, exatamente pela variedade de possibilidades que têm diante de si. Por isso, frequentemente terminam por escolher de maneira equivocada, como sucede com qualquer pessoa que é destreinada em uma determinada prática. Ela pode até entender o que está sendo feito, mas custa-lhe realizar aquilo que para outro, que possui um direcionamento na potência, é fácil e prazeroso.

Por meio dos hábitos, as potências livres passam a ter uma tendência para, dentro da multiplicidade de opções que se lhes apresentem, escolher uma delas com suavidade e facilidade. Ou seja, o hábito representa a tendência que se inseriu em uma potência, inclinando-a a determinada direção. Pode-se afirmar, portanto, que as virtudes são hábitos, isto é, qualidades estáveis, que levam ao bom uso e incremento de uma faculdade. Elas são necessárias para o bom exercício da potência, isto é, para que esta se desenvolva plenamente e exerça seus atos próprios com perfeição (ABBÀ, 2010, p. 188-189; TOMÁS DE AQUINO, S.T., I'-II ${ }^{\mathrm{ae}}$ q. 49 a. 4).

São chamadas de virtudes intelectuais aquelas que aprimoram a razão, e de virtudes morais as que aperfeiçoam a vontade e os apetites. As virtudes morais são as que tornam um ser humano efetivamente bom, porque cada um é melhor ou pior de acordo com suas decisões volitivas e com a maneira correta com que controla seus sentimentos e desejos. A presença de uma virtude moral indica que o sujeito provavelmente agirá da melhor maneira, tendo em vista sua bondade enquanto ser humano (PIEPER, 1966, p. 5-9).

Como estamos tratando do direito como um conhecimento possuído por alguém, conhecimento que se torna então um hábito ou propriedade do sujeito, cabe então entendê-lo como uma das virtudes intelectuais, isto é, ligadas à razão. Aristóteles, inaugurando uma tradição de séculos, defendeu que existem cinco dessas virtudes: a ciência (episteme), a inteligência (nous) e a sabedoria (sophia), que são primordialmente especulativas e teóricas; a arte ou técnica (techne) e a prudência (phronesis), que são práticas, voltadas para a ação (ARISTÓTELES, Ethic. 1. 6, c. 3; 1139, b, 14-18). Todas elas dizem respeito à verdade, inclusive aquelas relacionadas diretamente à prática ou ação. 
As virtudes teóricas - sabedoria, ciência e inteligência - e a técnica possibilitam ao ser humano a capacidade de realizar boas obras em termos intelectuais, mas não garantem que ele as empregará de maneira efetivamente boa, tendo em conta o bem integral do próprio sujeito e da sociedade. Apenas as virtudes morais asseguram que uma faculdade sempre será empregada corretamente, de acordo com os fins do ser humano. Portanto, as virtudes intelectuais permitem que se realizem ações moralmente reprováveis por meio delas - por exemplo, o uso abusivo ou antiético da ciência -, pois não regulam nem atingem a vontade e os apetites sensíveis do sujeito, que são os que garantem a bondade moral e integral do indivíduo (TOMÁS DE AQUINO, S.T., Iª -II ${ }^{\mathrm{ae}}$ q. 57 a. 1).

A única virtude que é, ao mesmo tempo, intelectual e moral é a prudência, pois regula a razão - e nisto é intelectual - enquanto esta guia e orienta a ação - o que caracteriza as virtudes morais.

\subsection{O CONCEITO DE CIÊNCIAS E SEU DESENVOLVIMENTO}

Para Aristóteles, a ciência trata do universal, isto é, daquilo que é idêntico em todos os lugares, sempre se comportando da mesma forma. Seriam verdades necessárias, e nesse sentido eternas e constantes (ARISTÓTELES, Ethic., l. 6, c. 3; 1139, b, 19 - 24). Com relação àquilo que pode ser de uma maneira ou de outra, não teríamos propriamente ciência.

Uma contribuição importante do filósofo grego foi aproximar o universal, o que se mantém íntegro e o mesmo em cada ente, das causas do próprio ente. Unimos vários entes distintos em uma mesma espécie quando reconhecemos neles a presença de idêntica forma, entendida esta em sentido metafísico. E, para o pensamento aristotélico, a forma é uma causa fundamental do ente. Diferentes indivíduos animais seriam cães, porque apresentariam a mesma forma substancial; o mesmo vale para as samambaias, os mosquitos, e assim por diante.

Conheceríamos verdadeiramente algo quando tivéssemos ciência de suas causas; antes disso, estaríamos no âmbito do amador, do diletante. A principal das causas é a formal, aquela que faz com que algo seja o que é, tenha aquela determinada essência, que se manifestará exteriormente em todo o relacionado ao ente em questão (OWENS, 1981, p. 25).

O conhecimento científico parte de fatos conhecidos, para então chegar a desconhecidos, buscando sempre as causas. Faz parte dele o processo de dedução, que visualizamos facilmente na matemática, mas também nas ciências naturais como a física e a química. Assim surgem as teorias, que posteriormente serão ou não confirmadas pelas experiências. A dedução é estudada pela lógica, 
que é uma ciência formal a respeito do exercício da razão humana. Ela estabelece regras para que um raciocínio seja bem realizado, não tendo em conta o conteúdo do que é pensado, mas as espécies de conceitos que são empregados (ARISTÓTELES, Pr. Anal., 24, b, 19 - 30).

Por sua vez, a indução parte do particular e tenta estabelecer regras gerais. A observação constante de um fenômeno leva a considerar que ele segue um padrão, ou seja, uma lei. Esta lei será geral, abarcando e explicando os casos individuais. O fato de o Sol surgir todos os dias indica uma estrutura fixa, que se repete todos os dias. Hoje, sabemos que se trata da rotação da Terra, da circunstância de ela girar em torno da estrela e de haver a força da gravitação atraindo os corpos entre si. Principiando em um fenômeno concreto, chegamos a uma explicação que está sustentada por uma lei geral (ARISTÓTELES, Top., l. 1, c. 12; 105, a, 10 - 19).

As leis gerais seriam manifestações da essência das realidades. Como estas são definidas pela essência, tenderão a se comportar de maneira similar em situações idênticas. Temos então os conhecimentos universais e necessários.

Segundo Aristóteles, tanto a dedução quanto a indução são empregadas nas ciências (ARISTÓTELES, Ethic., l. 6, c. 3; 1139, b, 25 - 36). É comum que determinada ciência use, como seu ponto de partida, conhecimentos obtidos por outra ciência. Dessarte, a geometria emprega conceitos da aritmética, e a perspectiva toma fundamentos na geometria.

Não parece haver grandes dificuldades em aplicar o quadro aristotélico das ciências para explicar os campos científicos contemporâneos. Basta ter em conta que as ciências quantitativas aristotélicas, largamente baseadas na matemática, e não a filosofia natural, estão mais próximas do que hoje compreendemos como ciências (OWENS, 1981, p. 31-32). É uma concepção de ciência mais estrita e reduzida da que empregamos usualmente hoje, mas isso não nos parece um defeito, e sim algo que auxilia separar tipos de saberes de acordo com notas importantes que os definem.

É evidente que o chamado método científico, com repetição de experiências controladas, que expandem a capacidade de observação do estudioso, auxiliou o êxito e o avanço de vários campos do saber. Porém, ele requer um corte, uma redução da realidade para algo controlável e mensurável. O que não pode ser medido fica fora do âmbito das ciências. Não que isso seja algo de errado, evidentemente; antes, é uma necessidade. Porém, não se pode esquecer de que se está diante de uma limitação (PORTIDES, 2008, p. 392).

Não há dúvida sobre o caráter científico das chamadas ciências naturais. Elas apresentam as características indicadas por Aristóteles e aceitas pelos vários cientistas que nelas trabalharam. Obtêm um conhecimento certo e universal, que servem para toda uma multiplicidade de seres, em condições 
bastante distintas. Elas permitem explicar o porquê de vários fenômenos, e também prevê-los. Esse caráter da previsibilidade serve de fundamento para uma concepção realista da ciência, ou seja, de que ela trata de algo em si real, e não de uma mera construção da mente humana. Ainda que também esta afirmação terminasse por ser contestada por pensadores que formaram a corrente antirrealista na filosofia da ciência (DEVITT, 2008, p. 224-235).

As ciências exatas adquiriram um prestígio enorme no Ocidente e, daí, para o resto do mundo. Há as vozes que lhe são críticas, por um motivo ou outro (NIETZSCHE, 1974, p. 334-336; 1977, p. 4-34), mas o fato é que a ciência adquiriu grande legitimidade em nossos tempos. Seus frutos encantam e trazem uma melhora indiscutível na vida material dos seres humanos, apesar de que nem sempre isso ocorra de maneira equilibrada e acessível a todos, e haver o preço do alheamento que surge ao lado da técnica.

Consequentemente, houve uma tendência a extrapolar o alcance das ciências. Cresceu a tentação de, por meio delas, buscar explicar todas as realidades, em qualquer âmbito. Nesse sentido, certas correntes do neodarwinismo ou da filosofia da mente, por exemplo, procuram mostrar que qualquer evento ou elemento - um ser vivo, um sentimento, um pensamento, a contemplação da beleza, etc. - nada mais são do que maneiras como a matéria se comporta. No fundo, tudo acaba resumido à física, chegando assim a uma explicação materialista de estilo mais forte (FESER, 2006, p. 49-84). A atração desse tipo de explanação está na sua simplicidade e facilidade, bem como no controle total que ela promete.

Há outras teorias cientificistas menos radicais que o materialismo, mas que igualmente sustentam que apenas o científico, compreendido como aquilo que pode ser mensurado, que é certo e universal, pode perfazer um conhecimento valioso. O resto, que não pudesse ser quantificado, cairia na vala comum das opiniões, do arbitrário e sem fundamento objetivo. Essa seria a postura, por exemplo, do Círculo de Viena e seus herdeiros intelectuais.

O enorme prestígio das ciências naturais levou a que muitos pensadores, dedicados aos campos do saber voltados para o ser humano e a sociedade, procurassem modelos exatos para as chamadas ciências humanas. Descartes buscou aplicar o método da matemática a todas as ciências, inclusive a medicina e a moral. Ele buscou provas irrefutáveis da existência de Deus, nos moldes formais do pensamento matemático. Sua filosofia valoriza primordialmente a certeza e clareza, tal como eram obtidas na aritmética (GILSON, 1950, p. 130-146).

Mais adiante, a física de Newton servirá de modelo para muitos filósofos, com a elaboração de um modelo expresso por meio de fórmulas quantitativas, em que uma parte se encaixa 
perfeitamente em outra, formando um todo que explica uma categoria inteira de fenômenos, sem se preocupar pela essência deles nem com o porquê de algo se comportar assim ou assado. É uma ciência descritiva. Kant ambicionará realizar no campo da filosofia o que Newton teria conseguido na física (GILSON, 1950, p. 226-230).

A sociologia de Comte é uma tentativa de análise científica do mundo do ser humano. Posteriormente, autores como Durkheim e Max Weber procurarão estabelecer constantes da sociedade, que funcionariam, de certa maneira, como fórmulas para prever os comportamentos e identificar as formas invariáveis que existiriam em todas, ou na maioria, das sociedades (STRAUSS, 1992, p. 36-80).

A economia, principalmente aquelas linhas que valorizam o uso do cálculo, também enveredou pelos caminhos das ciências naturais. Há a procura de fórmulas que expliquem os mercados, ou ao menos certos elementos da vida econômica, como as bolsas de valores, as taxas de câmbio e o consumo. Ao mesmo tempo, teóricos importantes reconhecem que, em vastos campos, o pensamento econômico não chega a ser uma ciência pura, com formato matemático, mas sim um conhecimento realizado com um instrumental próprio, regular, disciplinado, que seria também uma forma de saber científico (SCHUMPETER, 2006, p. 5-9).

A sociologia comteana e a economia de base matemática estão na fronteira entre as ciências naturais e as ciências sociais. Ainda que, pelos seus objetos, sejam hoje classificadas primordialmente como sociais. Uma característica, em todas essas ciências sociais, é o recurso a métodos estatísticos e a análises de dados. É uma tentativa de alcançar resultados semelhantes aos das ciências naturais, com maior ou menor sucesso. De fato, a estatística e o estudo de dados auxiliam em todas essas ciências - também no direito -; porém, elas não resolvem todos os problemas. Os dados precisam ser interpretados. Até para fazer as perguntas corretas, temos que ter uma teoria em certo grau de desenvolvimento.

Não há nelas a constância e certeza que podemos obter nas ciências naturais. Podemos descobrir tendências, que se repetem com maior ou menor frequência, mas não constantes absolutas (KINCAID, 2008, p. 594-597). Na economia, existem escolas que afirmam que as várias previsões se caracterizam por se equivocar quase sempre; os acertos seriam fortuitos (ROTHBARD, 1995, p. 17). Talvez haja um exagero nisso, mas é chamativo como conseguimos explicar poucas coisas, sempre de maneira precária e reduzida, no âmbito das ciências sociais (MACINTYRE, 2007, p. 88108).

Mais adiante, examinaremos algumas das maneiras pelas quais o direito foi classificado 
como uma ciência, o que continua sendo uma tendência relevante no estudo jurídico atual.

\subsection{A INTELIGÊNCIA OU COMPREENSÃO (NOUS) E A SABEDORIA (SOPHIA)}

Dentre as virtudes intelectuais, a inteligência seria o hábito que nos permite alcançar os primeiros princípios, sem os quais o pensar e o agir se tornariam impossíveis (ARISTÓTELES, Ethic., 1. 6, c. 6; 1140, b, 31 - 1141, a 8). Na visão de Aristóteles, esses primeiros princípios não são inatos, mas decorrem de maneira evidente de qualquer raciocínio que se faça. Eles surgem espontaneamente na alma, porque esta necessita deles para poder pensar e querer, e os percebe como evidentes e necessários.

Há primeiros princípios da razão teórica e primeiros princípios da ação. Exemplos dos primeiros são o princípio da não contradição, da identidade e o do terceiro excluído. Também existem primeiros princípios da razão prática, como o de fazer o bem e evitar o mal, respeitar os demais, ser justos, etc.

Nenhum desses princípios é demonstrável de forma cabal, mas apenas por argumentos ad hominem, que mostram a impossibilidade de refutá-los sem cair em contradição. Afinal, mesmo para negá-los, necessitamos contar com eles, o que mostra a sua indispensabilidade (ARISTÓTELES, Met. 1. 11, c. 5; 1162, a, 19 - b, 21). Ao refutar o princípio da não contradição, necessito empregar termos em um sentido determinado, não contraditório; o mesmo vale para a causalidade, pois enxergamos de forma imediata o encadeamento de causas em uma determinada conduta ou exposição teórica.

A partir desses primeiros princípios descobertos pelo nous, as ciências e demais virtudes intelectuais podem se desenvolver. Por meio da virtude intelectual da inteligência, Aristóteles e toda tradição que remonta a ele afastam-se do relativismo e do ceticismo. De acordo com essa tradição, é possível obter conhecimentos necessários e certos, que serviriam de base para todos os demais (IRWIN, 1988, p. 3-7).

Os conhecimentos derivados dos primeiros princípios não terão a força e a certeza destes, porque o que decorre dedutivamente de algo não pode ser mais forte que esse algo, como frequentemente sustenta Aristóteles e autores que o seguem neste ponto. Porém, tais conhecimentos derivados podem alcançar o grau de segurança necessário para se falar de uma ciência ou de sabedoria, por serem certos e universais.

As ciências costumam abranger uma esfera determinada do saber. Isso ajuda a caracterizálas, e também lhes permite esgotar e compreender melhor seus campos de estudo. Porém, o ser 
humano busca conhecer o fundamento último da realidade. Em outras palavras: por que existem coisas? Qual é a estrutura última do existente? Por que algo desaparece, e outro surge a partir dele? O que é o bem? O que vem a ser o conhecimento? O que significa a matéria, e o que a ordenou?

Esse saber sobre os fundamentos, sobre as causas primeiras e os fins últimos, caracterizando uma compreensão que procura ser total, é a sabedoria. O característico da filosofia é analisar cada aspecto da realidade segundo suas causas primeiras, obtendo uma visão de conjunto: colocando cada parte em seu lugar, relativamente às demais, ela pode enxergar o todo (PIEPER, 1963, p. 83-91).

As causas primeiras são em si as mais inteligíveis e primárias; contudo, não o são para nós, os seres humanos, e sim em si mesmas (ARISTÓTELES, Physic., 1. 1, c. 1; 184, a, 17 - 21). Essa diferenciação vem de nós conhecermos a partir dos sentidos, de que se conclui que temos mais facilidade em compreender o que é material, o que pode ser mensurado e percebido. Essa proximidade do nosso conhecimento com o material faz com que este esteja mais ao alcance da inteligência humana do que o imaterial, mas não significa que ele seja mais inteligível em si mesmo (ARISTÓTELES, Met., 1. 1, c. 2; 982, a, 20 - 983, a, 21).

O homem sábio conhece os primeiros princípios, que são as causas altíssimas, chegando assim a uma espécie de ciência dessas mesmas causas. Porém, não se trata de uma ciência limitada, como é a episteme, mas sim um conhecimento que abrange os aspectos fundamentais de tudo o que existe, ou seja, a sophia ou sabedoria (TOMÁS DE AQUINO, S.T., I ${ }^{\mathrm{a}}-\mathrm{II}^{\mathrm{ae}}$, q. 57 a. 2). Por isso, o sábio é capaz de julgar todas as outras coisas e ciências, colocando cada uma delas em seu devido lugar e sabendo diferenciar entre o que é mais importante e o que é secundário.

A sabedoria tem uma função arquitetônica, e busca uma verdade que está muitas vezes acima da capacidade humana. Além disso, a sabedoria não é um conhecimento voltado à produção, ou diretamente a algo prático. Ela é buscada por si mesma, porque seria o mais precioso que o ser humano poderia possuir.

Para Aristóteles, a sabedoria seria a filosofia, em especial a metafísica. Por ela, poderíamos conhecer Deus e todo o resto, chegando, de forma ordenada e hierarquizada, a uma visão panorâmica e global de tudo (ARISTÓTELES, Met., l. 1, c. 2; 982, a, 4 - 983, a, 12). Evidentemente, esse conhecimento poderia ser desenvolvido em suas partes, e o homem sábio iria cada vez entendendo melhor o relacionamento entre cada campo do saber, aprofundando no geral e no particular.

Podemos estudar as várias realidades - inclusive as ciências - desde um ponto de vista filosófico. De fato, a filosofia do direito - se ousarmos ir além do que o pensador grego afirmou expressamente - seria exatamente uma análise do direito segundo o ponto de vista dos filósofos, 
conforme veremos mais adiante. Porém, a filosofia por excelência seria a que examina o ser enquanto ser, não a partir de qualquer determinação ou corte da realidade. Seria uma forma radical de compreender, de perscrutar, de conhecer, sem qualquer limitação ou parcialidade. Logo, o que se obteria desta forma de saber seriam as verdades fundamentais, as causas primeiras, que servem de fundamento e terminam por explicar todo o resto (PIEPER, 1963, p. 83-96).

De acordo com essa concepção, a ética, a lógica, a política, a gnosiologia e mesmo a antropologia seriam filosofias secundárias, em relação à metafísica, que estaria acima de todas elas por representar uma virtude intelectual mais profunda e forte, que funcionaria como guia de todas as demais - a chamada função arquitetônica, ou organizadora, da filosofia no âmbito dos saberes (ARISTÓTELES, Met., l. 11, c. 3; 1061, b, 17 - 33).

\subsection{OS SABERES PRÁTICOS E DE PRODUÇÃO: PRUDÊNCIA E ARTE}

Após a análise das virtudes intelectuais teóricas, é o momento de estudar as virtudes práticas, aquelas que regulam um conhecimento cujo fim não é si mesmo, mas a obtenção de outras coisas além dele, ainda que por meio dele.

As virtudes práticas, pela sua própria natureza, dizem respeito a objetos ou realidades contingentes, particulares, e não às realidades universais e necessárias. Sobre estas últimas, é possível adquirir conhecimentos científicos; o mesmo não se dá no âmbito das virtudes intelectuais práticas.

Na Metafísica, posterior à Ética a Nicômaco, Aristóteles reconhece um caráter de universalidade à arte ou técnica, o que não sucede no escrito anterior. De qualquer modo, ele sustenta que todas as ações e produções, frutos das virtudes intelectuais práticas, referem-se ao particular (ARISTÓTELES, Met., l. I, c. 1; 981, a, 17 - 18). Portanto, a finalidade da arte é solucionar um problema concreto, produzir algo externo ao agente, e para isso será necessário um conhecimento de tipo prático, que levará em conta as experiências adquiridas pelo agente.

Com relação às virtudes práticas, é necessário ressaltar a diferença entre o agir e o fazer. Afinal, quanto ao que está fora de nós, ou agiremos sobre ele, ou o produziremos. Em ambos os casos, trata-se de algo prático, mas que pode ser compreendido a partir de pontos de vista diversos (PIEPER, 1966, p. 29-30).

O agir diz respeito a uma ação responsável, consciente, na qual estão envolvidos a vontade e os apetites, coordenados pela razão do sujeito. Há um controle do desenvolvimento da ação, em maior ou menor grau, que indica que o agente sabe a finalidade de sua conduta, busca tal finalidade, e por isso responde pela conduta. Aristóteles denominava o âmbito das ações de praxis. 
Uma das características das ações é que elas modificam quem as realiza, deixam nele uma forma ou tendência. Com as suas ações, as suas escolhas conscientes, o sujeito adquire virtudes ou vícios. Dessarte, ele se configura internamente, tornando-se um ser humano pleno, ou decaindo e fracassando em sua própria natureza (ARISTÓTELES, Ethic., l. 6, c. 7; 1141, b, 8 - 20).

Nesse sentido, as ações são dotadas de uma carga de imanência, pois marcam interiormente os agentes. Ademais, a ação não pode ser compreendida apenas olhando-a de fora; é necessário avaliar a intenção do agente, a ordenação dos seus apetites ao agir. Em outras palavras, medimos e qualificamos as ações tendo em conta o desígnio do agente, e não apenas o que surgiu externamente, a materialidade mecânica do movimento de quem se comporta. Por isso, condutas que externamente apresentem-se como idênticas podem ser, moralmente falando, boas ou ruins, dependendo dos motivos pelos quais foram levadas a cabo.

Como categoria distinta das ações, mas também relativas ao comportamento humano em seu sentido particular, prático e contingente, encontra-se o fazer, classificado por Aristóteles como poiesis, que frequentemente é traduzido por “produção”. Esse fazer ou produzir diz respeito à fabricação de algo externo a quem o pratica. Ao contrário do que se dá com a ação, a qualidade da produção pode ser medida de fora, porque se tratará de uma realização boa ou má, na medida em que o produto exterior for bem ou mal realizado (ARISTÓTELES, Ethic., 1. 6, c. 4; 1140, a, 1 - 6).

Quanto à produção, não importam as motivações do produtor, o porquê de ele ter confeccionado aquele artefato, a sua interioridade e a ordenação de seus apetites ao dar os passos que terminaram no artefato. Antes, analisa-se apenas o aspecto técnico, a manufatura do produzido, se este é adequado ou não à sua finalidade.

Na definição medieval que se tornou clássica, a prudência é a reta razão no agir, a recta ratio agibilium, enquanto a arte é a reta razão no fazer, a recta ratio factibilium. A prudência é a virtude que aperfeiçoa a razão humana, para que esta oriente convenientemente as operações ou ações dos agentes. Por meio dela, o ser humano pode realizar atos virtuosos, porque sua inteligência ilumina a vontade e mostra a esta o caminho para se alcançar o bem ético.

A prudência apresenta dois momentos: a deliberação e a eleição. A razão pesa as razões para agir de uma determinada forma, e no final indica a opção por um caminho específico (AUBENQUE, 1999, p. 123-163). Não será uma boa eleição se for realizada por motivos equivocados, desordenados, desconformes com a razão; exige a integridade do ato, sua perfeição completa. Em outras palavras, a intenção do agente ao ponderar e eleger é importante para caracterizar a ação prudente. Como é fácil observar, a eleição no término da deliberação será realizada em vista de uma situação concreta, 
específica, e não de modo abstrato ou geral. Por isso, a prudência é um saber prático.

A pessoa prudente delibera tendo em vista o que é favorável para uma vida feliz, entendida esta em um sentido global (BERTI, 2014, p. 56). As ações escolhidas e aperfeiçoadas pela prudência não têm um alcance limitado a um aspecto da existência do sujeito, mas visam à sua plenitude como um todo, à vida boa (ARISTÓTELES, Ethic., l. VI, c. 5; 1140, a, 25 - 28). As ações prudentes tornam o agente bom enquanto ser humano, de forma global e radical, e não em um sentido específico, tal como se daria se o aperfeiçoasse unicamente como professor, sapateiro ou jogador de xadrez.

Paralelamente, a arte ou técnica é a capacidade intelectual que nos possibilita produzir da melhor maneira, com precisão e maestria (ARISTÓTELES, Ethic., l. VI, c. 4; 1140, a, 6-10). Como ela visa a uma realização externa, as várias artes diferenciam-se entre si pela finalidade que almejam. Daí a caracterização da construção civil, da gastronomia, da marcenaria, da capacidade de discursar, da pintura, e assim por diante.

As artes exigem flexibilidade, adaptação, visão clara do fim e conhecimento dos meios para alcançá-lo. Admiramos o virtuosismo de um músico ou a criatividade de um compositor, assim como a habilidade de um artista de circo ou de um confeiteiro. Em todos esses campos, analisamos o que é realizado; não se a pessoa está ou não se tornando melhor, em termos globais, com aquilo. E verificamos o produto que fizeram, o resultado obtido, tendo pouca importância se o técnico fracassou, apesar de ter trabalhado com a melhor das intenções.

Com o desenvolvimento da arte, percebemos que ela é regida por regras. Há combinações e passos que ajudam a alcançar o produto almejado, enquanto outras providências causam deficiências. É preciso haver treino, prática, reflexão, conquista de habilidades - inclusive corporais ou manuais -, em vários casos. À medida que vamos aprendendo a dominar a técnica, somos também mais capazes - como regra geral - de julgar a qualidade dos produtos feitos por outros. Habitualmente, a arte é aprendida com a ajuda de um mestre, que orienta o aprendiz a superar as dificuldades daquele âmbito. É comum que se forme uma corporação, um conjunto de praticantes, que se ajudam no aperfeiçoamento mútuo dentro daquela técnica (MACINTYRE, 2007, p. 187-190).

A maestria na arte permite tanto que o artífice se esmere em excelentes obras, produzindo em conformidade com as regras de seu fazer, quanto que ele realize produtos defeituosos. Quem conhece bem as regras da produção sabe também burlá-las ou empregá-las inadequadamente. O mesmo não se dá com a prudência, no âmbito da ação: esta apenas permite que se aja bem, em conformidade com um fim adequado ao sujeito agente. Agir mal não é prova de domínio e alto grau de prudência, mas sim de falta dela. 


\section{O DIREITO NO QUADRO DAS VIRTUDES INTELECTUAIS}

Nesta segunda parte, procurar-se-á estabelecer em quais das virtudes intelectuais o direito pode ser mais bem classificado, levando em conta as noções estabelecidas por Aristóteles e a tradição que as desenvolveu. Foi necessário fazer uma exposição longa a respeito das virtudes intelectuais, sem nos referirmos diretamente ao direito. Esperamos que a transição para o jurídico se torne facilitada pelo escrito nos pontos anteriores.

Haverá uma série de consequências teóricas e práticas relevantes a partir das conclusões que forem alcançadas a partir de agora, pois cada tipo de virtude intelectual implica um grau de certeza alcançável diferente, bem como uma metodologia específica a ser empregada, na maneira de estudar e dominar aquele âmbito do conhecimento.

A esse respeito, há algumas palavras de Aristóteles que, por tocarem em aspectos relevantes, são fartamente citadas:

Constitui a marca de uma mente instruída esperar aquele grau de precisão em cada modalidade que é permitido pela natureza do assunto em particular. É igualmente implausível aceitar conclusões meramente prováveis de um matemático e exigir demonstrações rigorosas de um orador (ARISTÓTELES, Ethic., l. I, c. 3; 1094, b, 23 - 27).

Não será possível fazer aqui análises profundas, como mereceriam várias das correntes e escolas que serão citadas. Serão apenas apresentados elementos que permitam revelar qual tipo de conhecimento, de virtude intelectual, é o direito, observando o que juristas importantes afirmaram a respeito.

\subsection{O DIREITO COMO CIÊNCIA}

Nos últimos dois séculos, houve uma preocupação acentuada em tratar o direito como uma ciência. Em parte, isso foi fruto da valorização do saber científico no mundo ocidental, à qual já se referiu acima. Além disso, motivou essa tendência à ciência a procura de um direito certo, seguro, claro, que não estivesse sujeito a muitas interpretações ou incoerências. Antes, seria um conhecimento firme, sobre o qual poderiam se apoiar o Estado e os particulares, a fim de regerem as próprias condutas com previsão e tranquilidade (PONTES DE MIRANDA, 2012, p. 14).

Elevar o direito à categoria de ciência, portanto, teria por efeito que os direitos dos cidadãos fossem respeitados e se achassem fundamentados de maneira científica. Logo, seriam acessíveis e poderiam ser defendidos por todos que empregassem os métodos corretos e dedicassem o tempo necessário ao seu estudo. A cientificidade implica universalidade, neutralidade, e isso era desejável 
para o direito. A sociedade tecnológica e a burocracia administrativa, bem como a economia de mercado, necessitariam de um direito previsível, neutro aos valores e racional (NEUMANN, 2002, p. 463-466).

Ao mesmo tempo, o Estado produziria a legislação de maneira razoável, levando então que toda a sociedade obedecesse a normas cuja criação seguiu um procedimento anteriormente estabelecido e que apresentariam um conteúdo conforme com os valores de todo o sistema jurídico. Isso era interessante para os negócios e para o aumento geral da eficácia na administração pública e privada (BARZOTTO, 1999, p. 13-17; FERRAZ JÚNIOR, 2015, p. 44-45).

Nessa procura de informar o direito de um caráter científico, podemos distinguir o trabalho de vários autores, que irão por caminhos marcadamente diversos uns dos outros. Em certa medida, chega a ser difícil colocar, em um mesmo conjunto, concepções tão díspares do direito e da ciência, pois há o perigo de generalizações indevidas e da superficialidade. Contudo, é importante observar como a preocupação de criar uma “ciência do direito”, nos moldes das outras ciências - naturais ou sociais - gerou relevantes linhas de pensamento e de entendimento do jurídico.

Dentre os vários exemplos de formulação do direito como ciência, iniciaremos com a análise da Pandectística, movimento do século XIX no qual se destacaram juristas alemães como Savigny, Puchta e Windscheid. Essa escola projetava elaborar uma ciência jurídica baseada em conceitos formais, que teriam sido extraídos justamente do direito romano e auxiliariam a compreensão e manuseio de todos os campos do direito (KAUFMANN, 2002, p. 167-169).

A noção de direito subjetivo, suas relações com o direito objetivo, a relação jurídica, o objeto de direito, o fato jurídico, a pretensão, o dever e a obrigação seriam exemplos desses conceitos estruturais da ciência do direito, que se tornaram patrimônio comum de grande parte do direito civil e da teoria do direito atuais (LARENZ, 1997, p. 9-39).

A Pandectística foi influenciada profundamente pelos sistemas jusracionalistas dos séculos anteriores (WIEACKER, 1980, p. 427). Seu nome é devido a que os autores que dela formaram parte estudavam primordialmente as Pandectas ou Digesto, a compilação de textos de juristas da época romana. O Digesto era parte integrante do Corpus Iuris Civilis, o conjunto de textos jurídicos e normas elaborados por uma comissão, criada por ordem do imperador Justiniano e cujos trabalhos terminaram em 534.

De certo modo, é neste momento, no seio da Escola das Pandectas, que surge a disciplina da teoria geral do direito, que se diferenciaria logo da filosofia do direito e dos campos jurídicos de aplicação mais imediata, como o direito penal, o direito civil e o direito comercial. Sempre com a 
intenção de alcançar um grau científico no direito, que independeria, nesse nível, das normas concretas, mas construiria um conhecimento universal. Tal conhecimento universal, geral, permitiria que as normas particulares fossem devidamente absorvidas, interpretadas e aplicadas de forma rigorosa, consistente, científica.

O movimento pandectista pode ser considerado uma tentativa de aplicação, ao direito, dos critérios próprios de uma ciência da natureza, no sentido que falamos acima, de modo especial nas obras do primeiro Jhering (LARENZ, 1997, p. 29-33), e também da ciência histórica, que Savigny enxergava como ligada à filosofia e ao saber teórico (WIEACKER, 1980, p. 438; LARENZ, 1997, p. 9-10). Essa dependência em relação às ciências positivas e históricas é efeito da ligação dos pandectistas com o espírito de sua época, que os empurrava para a confecção de uma ciência rigorosa e sistemática.

Ainda mais radical, no sentido de sustentar uma concepção científica, formal e sistemática do direito, foi a proposta por Hans Kelsen em sua Teoria pura do direito. A primeira edição dessa obra é de 1934; a segunda, com importantes alterações, é de 1960. Para Kelsen, era necessário compreender o direito com critérios próprios, unicamente jurídicos, de modo que ele não precisasse - nem devesse - recorrer a aspectos ligados à legitimidade das normas, aos valores que elas consagrassem, nem à aplicação efetiva delas no meio social. Seria uma ciência puramente jurídica, e não política, sociológica ou, menos ainda, moral (KELSEN, 2009, p. XI; p. 1).

A construção teórica de Kelsen foi muito influente. Com base na lógica e em uma interpretação da filosofia kantiana, ele defendia que são normas jurídicas aquelas que fazem parte do ordenamento jurídico, no qual entraram e foram produzidas da maneira prevista pelo próprio direito. Assim, seria o direito que decidiria quais eram as normas jurídicas, porque elas seguiriam as leis previstas para o estabelecimento das normas (KELSEN, 2009, p. 215-221).

Chegaríamos a normas jurídicas, constituídas juridicamente, em uma ciência pura. Não caberia questionar o conteúdo das normas, mas apenas a sua juridicidade, que diz respeito à validade e à harmonia com regras superiores (KELSEN, 2009, p. 221-224).

Kelsen diferencia a ciência jurídica, que seria social normativa, das ciências naturais. A primeira estaria regida pelo princípio da imputação, porque suas normas determinam como a conduta humana deve ser, não como é. Assim, se alguém roubou, deverá ser punido com a pena prevista na norma jurídica. Por sua vez, as ciências naturais têm proposições que indicam como as realidades são, fundadas no princípio da causalidade. Por exemplo: se uma esfera de ferro for esquentada, ela será dilatada (KELSEN, 2009, p. 84-87). 
Outra tentativa de transformar o direito em ciência, porém por um caminho oposto a qualquer tipo de formalismo, é a dos chamados realistas, que tiveram como antecessor o juiz Oliver Wendel Holmes. Trata-se de uma corrente primordialmente americana, ainda que tenha influenciado outros países, notadamente os escandinavos (LEITER, 2005, p. 50).

Para os realistas, direito é o que é decidido pelos tribunais, ou seja, o que efetivamente é aplicado por quem emite sentenças e resolve as pendências. Nas palavras de Holmes, o objeto do estudo jurídico é a predição de como será a incidência da força pública mediante a instrumentalidade das cortes de justiça (HOLMES JR., 2009, p. 3). Consequentemente, o ponto de vista pelo qual ele deve ser estudado é o do aplicador do direito, e não do teórico (POSTEMA, 2011, p. 43).

Então, o direito seria uma ciência de previsão, que usaria de métodos de pesquisa quantitativos, de cunho sociológico, voltados primordialmente para o comportamento dos magistrados e suas cortes. Tal foi a posição defendida, com diferentes matizes, por realistas de destaque, como Roscoe Pound, Oliphant e Llewellyn (POSTEMA, 2011, p. 127-131).

No fundo da visão dos realistas, há, de certa maneira, uma noção sobre o direito próxima do positivismo. Eles defendem que argumentos morais deveriam ser deixados de lado em favor dos jurídicos, porque estes poderiam ser verdadeiramente científicos, enquanto os outros seriam subjetivos e inseguros. Portanto, se não acreditam na possibilidade de uma ciência formal do direito, nem por isso deixam de buscar um direito científico, inclusive apoiado em outras ciências que auxiliem na previsibilidade, como a economia, a política e a psicologia (POSTEMA, 2011, p. 124126).

Também com base marcadamente sociológica apresenta-se a concepção daqueles que defendem que o jurídico se resume, de certa forma, ao que é seguido pela sociedade, às normas que efetivamente guiam o comportamento dos indivíduos e das instituições. Em outras palavras, normas seriam antes de tudo aquelas de eficácia social, não importando tanto se elas são ou não válidas em sentido formal ou técnico. Teríamos então o direito técnico, ou positivo, mas também normas de não direito, que apresentariam efetividade social e disputariam espaço com as normas positivas e formais (CARBONNIER, 2001).

Aquelas normas, socialmente consideradas como vinculantes, e que os cidadãos aceitam que sejam reforçadas pela coerção, sendo que frequentemente as seguem apenas por considerarem que elas são razoáveis e satisfazem suas necessidades de organização social, configurariam o direito realmente vigente, ao lado do não direito. O nível de existência do direito formal varia entre os sociólogos; de qualquer modo, eles quase sempre sustentarão que a sociedade é regulamentada em 
larga medida por regras não jurídicas, que não tiveram por fonte o Estado e seus órgãos de poder, e sim a evolução da sociedade, contemplada pela sociologia.

Enquanto a versão anterior do realismo jurídico voltava-se para a orientação dos tribunais e dos juízes, esta segunda versão se funda no comportamento social como um todo.

Como conclusão dessas considerações acerca do direito e da ciência, pode-se estabelecer que, se entendermos ciência em uma acepção ampla, que abarque todos os conhecimentos que são estudados de forma orgânica e consistente, visando empregar métodos ao menos em certa medida rigorosos, então podemos efetivamente considerar o saber jurídico como uma ciência. Evidentemente, não será uma maneira exata, porque o direito não atinge a universalidade própria da episteme aristotélica, nem chega a afirmações verdadeiras de modo necessário. Ao menos, chega a poucas delas. Mas, se o contraposto ao científico é o conhecimento vulgar, sem busca de causas e apenas experiencial, então o direito é uma ciência, porque exibe um rigor e seriedade superiores ao saber espontâneo (REALE, 2002, p. 53-56).

Contudo, ainda que possamos classificar o direito como ciência, ele deveria ser incluído entre os saberes práticos, e não teóricos. Neste ponto, parece que vários autores separaram a aplicação do direito do seu conhecimento, o que, na maior parte das vezes, será artificial e mesmo equivocado (em certa medida, KELSEN, 2009, p. 80-84). Trata-se de um ramo do saber em que o estudo tem uma função primordialmente prática, e não de mera contemplação da verdade, como se dá nas ciências naturais ou na filosofia ${ }^{1}$.

Em outras palavras, conhece-se o direito para aplicá-lo, para realizá-lo. Não há dúvida de que se pode abordá-lo com interesse apenas teórico, mas isso nunca será o fundamental, como se dá nas ciências naturais. Por isso, qualquer explicação satisfatória do direito deverá abranger a sua utilização na sociedade, a maneira como ele é ou foi manuseado pelos que o operam ou operaram. Sem isso, teríamos uma explicação defeituosa, pois se deixaria de lado o motivo pelo qual aquele campo do conhecimento se formou, que foi para a regulamentação da sociedade e a distribuição dos direitos dos seus membros.

\subsection{O DIREITO COMO SABEDORIA}

O estudo do direito envolve um campo delimitado da realidade. Enquanto jurista, o estudioso não tem a pretensão de chegar às explicações últimas, às causas primeiras de tudo o que existe, que

\footnotetext{
${ }^{1}$ Considerações em sentido diverso, mas com pontos em comum, estão em SHECAIRA, 2015.
} 
são precisamente o objeto da sabedoria. Mesmo no âmbito da sociedade, o direito trata das relações de justiça dos indivíduos entre si e com a sociedade. Logo, seria exagerado considerar o direito como uma sabedoria.

Por outro lado, um dos sentidos em que Aristóteles considera que se possa falar de sabedoria é o da qualidade de quem excede, esmera-se de maneira superior em um campo do saber ou arte (ARISTÓTELES, Ethic., 1. 6, c. 7; 1141, a, 9-10). Então, determinado cientista, matemático ou artista seriam sábios, porque dominam plenamente sua área de especialidade. Porém, este não é o sentido primário de sabedoria, mas uma derivação analógica: de modo similar a como o sábio conhece as causas primeiras de toda realidade, o sábio especializado consegue vislumbrar de forma ampla aquele seu campo específico de conhecimento.

Nesse sentido derivado, pode-se reconhecer a existência de uma sabedoria jurídica, de forma similar a como há sabedorias em outros campos (econômico, político, médico, etc.). Ela se mostra em uma visão profunda, que entende as finalidades e os elementos do direito de maneira sólida, permitindo que se descubram relações e se percebam aporias que às vezes passam despercebidas mesmo para o especialista (PONTES DE MIRANDA, 2012, p. 23-24). Normalmente, essa sabedoria jurídica implica o conhecimento sério de mais de um dos campos jurídicos, além de uma base segura de filosofia e teoria geral do direito. É o que encontramos em juristas como Savigny, Del Vecchio, Radbruch, Gény e tantos outros.

Uma característica desses sábios do direito é a capacidade de transitar em várias áreas; talvez nem sempre com igual profundidade e acerto, mas frequentemente de maneira criativa, sensata, consistente. Adquiriu-se a visão arquitetônica, que permite discernir se determinada solução ou construção teórica é razoável ou não. Esse olhar geral faz com que os problemas e equívocos vigentes em uma área particular do direito fiquem mais evidentes aos olhos desses juristas, ainda que lhes possa faltar um conhecimento mais específico sobre aquele campo em questão (KIRSTE, 2013, p. 33-34).

Se voltarmos para o sentido mais estrito de sabedoria, do conhecimento de toda realidade pelas últimas causas, notamos que ela pode ter o direito como seu objeto, de forma similar a como lhe servem de elemento de estudo todas as matérias relevantes para o ser humano e o cosmos. Daí que falemos, com toda propriedade, da filosofia do direito, disciplina que é precisamente a reflexão filosófica, sapiencial, sobre o direito (FERRAZ JÚNIOR, 2015, p. 22-23).

Então, não é o direito que é uma filosofia, mas ele é tratado, meditado e estudado pela filosofia. O fenômeno jurídico é de interesse dos filósofos, pois constitui parte relevante do 
comportamento do indivíduo e da sociedade, que se mantém como uma constante - ainda que com diferenças no tempo e no espaço - sempre que há grupos humanos organizados.

As questões sobre o fundamento do direito, sua estrutura, a legitimidade das normas, sua função dentro da sociedade, sua relação com outras ciências, o método próprio a ser utilizado em sua aplicação, o grau de certeza que nele é possível atingir, a própria definição de direito, e outras semelhantes a estas são tratadas pela filosofia do direito. O conhecimento jurídico pressupõe as conclusões alcançadas pela filosofia do direito, mas não cabe a ele chegar a elas. São respostas que estão além do âmbito do propriamente jurídico, mas que explicam como este funciona e tornam viável a sua existência (KIRSTE, 2013, p. 30-32).

Assim como o direito pode ser tema da filosofia, sem por isso ser classificado propriamente na virtude intelectual da sabedoria, ele pode ser objeto da sociologia, o que faz surgir a sociologia jurídica, disciplina também distinta do direito, mas a ele estreitamente ligada. Cabe indicar várias outras disciplinas que têm essa mesma relação com o direito: não se confundem com ele, mas estudam-no e ajudam a compreendê-lo melhor. Entrariam nessa categoria, por exemplo, a psicologia judiciária, a criminologia, a história do direito e a lógica jurídica.

\subsection{O DIREITO COMO ARTE}

A concepção do direito como uma arte ou técnica está clara no direito romano clássico. No primeiro texto do Digesto, tirado de uma obra de Ulpiano, está escrito: “como Celso define elegantemente, o direito é a arte do bom e do justo” (Dig. 1.1.1. pr)². Ulpiano, agora por suas próprias palavras, afirmou: “A jurisprudência é o conhecimento, a informação das coisas divinas e humanas, a ciência do justo e do injusto” (Dig. 1.1.10.2)

Nos textos romanos, há uma variação ligeira no emprego dos termos “ciência” e “arte”, mas o sentido prevalente é este último, conforme estabelecido por Aristóteles. O termo “ciência” está utilizado no sentido mais amplo de conhecimento, de saber; ora, a arte, tal qual visto anteriormente, é uma forma de conhecimento, uma virtude intelectual, assim como a ciência em sentido estrito.

Portanto, para os romanos, a classificação mais própria do direito é como uma espécie de arte. E isso se mostra como razoável e convincente. Afinal, no saber jurídico, há uma finalidade prática evidente. O estudo das leis e das normas visa solucionar situações concretas, organizar a

\footnotetext{
${ }^{2}$ Nam, ut eleganter celsus definit, ius est ars boni et aequi.

${ }^{3}$ Iurisprudentia est divinarum atque humanarum rerum notitia, iusti atque iniusti scientia.
} 
sociedade, estabelecer o que é devido a cada um. Por isso, deve ser complementado com o conhecimento da situação fática, do que pedem as partes, do problema que está sendo exposto.

Podemos estudar as normas sem um interesse imediato prático. Por exemplo, buscando sua concatenação lógica, desvendando seu significado. Porém, a finalidade do jurista e do direito será, primordialmente, algo prático. Não é à toa que a noção de norma, tão fundamental para os positivistas, implica um direcionamento, uma ordem, ou seja, visa a um resultado (BOBBIO, 1993, p. 79-82). Ainda que tal resultado não se alcance, a norma continua a existir e a ser vigente, sem dúvida; porém, ela foi elaborada por uma razão de eficácia, não para uma construção mental teórica.

Aliás, a construção teórica que vier a ser feita terá como objeto uma realidade voltada para o fazer, para modificar o mundo exterior. Não se limitará ao saber, à teoria, como se estes fossem fins em si mesmos. Antes, o direito é um conhecimento que visa a algo além do próprio conhecimento, uma aplicação. É semelhante ao que sucede com a medicina e a engenharia, que são aplicações de ciências teóricas com vista a um realizar (observações interessantes, ainda que em parte distintas das feitas neste texto, em HEIDEGGER, 1977, p. 4-14).

Sendo voltado para as realidades práticas, o direito depara-se com o contingente. Ele estuda as realidades universais e gerais, o que é necessário, mas não visando simplesmente ao seu conhecimento. A busca do direito é a solução de problemas, a orientação da sociedade e das condutas, a organização das relações sociais. Não qualquer orientação, mas de modo a que se alcance um bem determinado, que é a própria coisa justa, a relação equilibrada entre os seres humanos e os bens externos no seio da sociedade. Portanto, visa a um fim prático, que será realizado dentro de uma realidade essencialmente mutável, precária, problemática, que são as relações sociais (SCHULZ, 1936, p. 64-65).

O estudo das normas poderia, em tese, ser algo simples e mais seguro, desde que elas não se modificassem frequentemente. Porém, o direito não tem por fim esse estudo movido pelo seu próprio valor especulativo ou teórico, de acordo com o que expusemos; ele necessita do exame e do conhecimento das leis para aplicá-las, para moldar o que é informe em algo justo, apaziguador, equilibrado, dando a cada um o que lhe é devido.

A convicção de que o direito é plástico, flexível, sempre aperfeiçoável, era cara aos romanos. Um jurista antigo, Javoleno, escreveu: “Toda definição no direito civil [o direito da cidade] é perigosa: há muito pouco que não possa ser subvertido” (Dig. 50.17.202) ${ }^{4}$. Essa afirmação contraria frontalmente a ambição dos pandectistas alemães, de construir uma ciência com base em conceitos

\footnotetext{
${ }^{4}$ Omnis definitio in iure civili periculosa est: parum est enim, ut non subverti posset.
} 
neutros, científicos e universais. Conceitos desse teor dificilmente são encontráveis no mundo do direito, pela própria matéria que lhe diz respeito. Estamos no âmbito do contingente, do particular, e não do universal e necessário.

No seio de uma arte, as regras ou normas têm uma função diretiva, sem dúvida fundamental. Aliás, certas regras praticamente nunca devem ser desobedecidas, porque trariam um defeito grave ao produto buscado pelo fazer do artífice. Contudo, o uso das regras tem um sentido, visam a algo. Ter consciência disso permite manuseá-las da melhor maneira possível, que precisará ser criativa em casos inauditos ou inéditos - os chamados atualmente de hard cases -, enquanto tenderá a ser mais rotineira naquelas situações repetitivas, a respeito das quais a solução mais correta já foi estabelecida.

Aqui podemos, novamente, aprender dos juristas romanos. Neste caso, de Paulo:

O direito não é obtido [tomado] da regra, mas do direito que a regra é feita. Portanto, pela regra é entregue uma breve narração das coisas, e, como diz Sabino [outro jurista romano], como é uma conexão de causa, uma vez em que esteja viciada em algo, perde a sua função (Dig. 50.17.1)

Pela arte do direito, surgiram as regras jurídicas; não o contrário. Grande parte das normas sob as quais hoje vivemos, especialmente no campo do direito privado, teve sua origem no direito romano e medieval. Ou seja, os artífices do direito, os juristas, tendo diante de si casos concretos, descobriram regras universais, de caráter prático, que permitiram desenvolver e enriquecer a própria arte. Essas regras, posteriormente, foram estatizadas; porém, sua origem é o saber, o conhecimento dos especialistas.

Vimos antes que a arte é a recta ratio factibilium, ligada ao fazer, à produção. Não seria, contudo, absurdo relacionar o direito a tipos de saber como a culinária, a marcenaria, a construção, a costura, e vários outros semelhantes?

Podemos ter uma visão demasiado material e estreita das artes e das técnicas, esquecendo que a retórica, as belas-artes, a política, a estratégia militar e a administração de empresas também são contadas entre elas. O que diferencia uma arte da outra é a sua finalidade, e todas elas visam a um produto que lhe é característico. Daí que as técnicas possam ser marcadamente distintas umas das outras, com graus de nobreza diferentes, embora todas mostrem uma maestria e domínio que, dentro do seu escopo, poderão ser admiráveis.

No caso do direito, estamos diante de uma das mais nobres artes. Em Roma, essa arte passou a ser exercida por uma corporação, um grupo de pessoas que começou a se dedicar profissionalmente

\footnotetext{
${ }^{5}$ Non ex regula ius sumatur, sed ex iure quod est regula fiat. per regulam igitur brevis rerum narratio traditur, et, ut ait sabinus, quasi causae coniectio est, quae simul cum in aliquo vitiata est, perdit officium suum.
} 
a esse saber. Por isso, adquiriram nele uma excelência que até então não existia, e essa técnica desenvolvida foi um dos mais importantes legados dos romanos para a sociedade ocidental (SCHULZ, 1946, p. 117-118).

Hoje em dia, os juristas tornam a ressaltar e valorizar o aspecto técnico, de arte, do direito. Ainda que com uma base filosófica diferente da aristotélica, e sem tratar de elementos a nosso ver importantes, Tércio Sampaio Ferraz Júnior, por exemplo, defende que o direito atual é tecnológico, no sentido de possuir complexos argumentativos, fórmulas persuasivas - e não proposições descritivas, próprias das ciências -, que visam garantir a decidibilidade de possíveis conflitos (FERRAZ JÚNIOR, 2015, p. 58). A proximidade da techne de Aristóteles é clara, sem que haja uma semelhança completa.

Caberia perguntar qual seria a finalidade da arte jurídica, isto é, qual o produto por ela realizado. Trata-se de um tema complexo, que envolve aspectos que vão além do pretendido neste texto. No entanto, pode-se indicar aqui, com base nas palavras de Ulpiano, citadas no início deste ponto, sobre o direito como a arte do bom e do justo, que a poiesis jurídica é exatamente o justo, a coisa justa, que é aquela devida a alguém. A arte do direito visa discernir e apontar o que é o justo, o ajustado, o correto, o devido a cada pessoa envolvida em uma relação com outras. Esse justo seria o ius, o próprio direito, que se configura assim como a ipsa res justa (ORREGO, 2005, p. 141-153).

Tal produto tem as características daqueles que servem de objeto para a arte: é contingente, concreto, pode ser feito de um jeito ou outro. É algo prático, não se satisfazendo em ser um conhecimento que se fecha em si mesmo. Finalmente, seu valor mede-se pela qualidade da coisa realizada, e não pela intenção de quem a trouxe à luz. Este último aspecto é o que diferenciará o direito da prudência.

\subsection{O DIREITO E A PRUDÊNCIA}

Tanto a prudência quanto a técnica são saberes práticos, relacionados ao contingente e ao comportamento humano. Porém, conforme visto anteriormente, a prudência diz respeito ao agir, à praxis, enquanto a técnica regula o fazer, a poiesis.

O agir corresponde às ações entendidas como humanas, nas quais o fim é desejado pelo agente, que controla seus atos em vista desse mesmo fim. Como a vontade e os apetites sensíveis possuem um papel preponderante na praxis, eles têm que estar bem ordenados para que ela seja perfeita. Apetites desordenados tornam a ação ruim, ainda que externamente ela aparente ser boa; é o que se dá com algo feito por hipocrisia, ou por segundas intenções nocivas, ou simplesmente para 
se obter uma vantagem ilícita. A suposta bondade objetiva, que foi realizada externamente, não torna o agente virtuoso, porque as disposições dele foram equivocadas ou degeneradas (ARISTÓTELES, Ethic., 1. 2, c. 6; 1106, b, 8 - 28).

Pelo contrário, a poiesis tem a sua bondade medida não pelas intenções do artista, e sim pela qualidade objetiva do produto feito. A um artífice, enquanto tal, não se honra pela vontade com que realizou a obra, mas sim se esta foi satisfatória, se atingiu sua finalidade como artefato (TOMÁS DE AQUINO, S. T., I ${ }^{\mathrm{a}}-\mathrm{II}^{\mathrm{ae}}$ q. 57 a. 3).

Ademais, ainda que compartilhe com a prudência o fato de ser relativa a objetos contingentes e à razão prática, a arte diferencia-se dela porque simplesmente confere a possibilidade de realizar boas ações, no sentido técnico, mas não garante que elas sejam levadas a cabo de forma moralmente aceitável, exatamente porque dependerão da vontade reta do agente. Já a prudência não apenas possibilita, mas assegura com a sua presença que a conduta será boa, no sentido de virtuosa, tendo em conta o bem do ser humano como um todo, e não apenas como artista.

Essa limitação da técnica em propiciar a possibilidade, e não a garantia, de fazer o bem moral é característico também das virtudes intelectuais especulativas, como a ciência e a sabedoria. Por isso, dentre todas as virtudes intelectuais, isto é, que aperfeiçoam a razão, apenas a prudência é considerada igualmente uma virtude moral, porque retifica a ação humana em seu sentido mais profundo e radical, de uma conduta querida, responsável e dirigida a um fim que modifica - aprimorando ou deteriorando - o próprio agente que a leva a cabo.

Tendo essas diferenças em conta, torna-se fácil concluir que o direito é principalmente uma arte, porque ele não garante que o jurista ou as partes interessadas ajam de uma maneira correta interiormente. Ele se limita ao aspecto exterior, a algo produzido; é uma técnica que permite descobrir qual é o justo no caso concreto, aquilo que é devido para os envolvidos em uma relação em torno de bens externos. A bondade do direito é medida pela adequação mesma da solução proposta para um determinado litígio, e não pela vontade reta das partes envolvidas (uma argumentação distinta: FINNIS, 2011, p. 283).

\section{CONCLUSÃO}

A consideração do direito como uma arte traz importantes consequências no seu entendimento e na sua aplicação. A técnica não permite regras absolutas e gerais, nem soluções ou fórmulas acabadas e indiscutíveis. Na medida em que nos aproximamos às coisas reais, ao que existe de forma concreta, as circunstâncias e contingências ganham força. O universal vai perdendo sua 
clareza no individual em que ele se materializa. O reino do comportamento humano e dos artefatos é complexo e opaco, e o jurista precisa aceitar que seu trabalho não permitirá a certeza e a exatidão encontradas em outros âmbitos.

A forma de estudar o direito precisa levar em conta que estamos diante de uma técnica. Por isso, é preciso examinar como os tribunais a aplicam, o método para a interpretação das normas, o caminho pelo qual as partes vivem o jurídico, e assim por diante. Não é possível limitar-se a uma análise lógica, apenas com a leitura de textos normativos ou construção de teorias abstratas. Esse pensamento mais geral também tem sua importância, mas de maneira instrumental: ele auxilia a arte jurídica e não é um fim em si mesmo.

O direito exige treino, para chegar à capacidade de distinguir o que é o justo, o jurídico em uma situação concreta. Na formação de um jurista, entram doses consideráveis de apuro teórico; porém, também necessita entrar o conhecimento experiencial da vida, dos seres humanos, da sociedade. Refletindo sobre isso, pode-se então obter a maestria em uma arte que é fundamental para o mundo em que vivemos.

Tentar manusear o direito como se ele pertencesse a outra categoria - especialmente a ciência ou a prudência - é possível, em certa medida. Porém, deve ser feito com cautela. Caso contrário, o desajuste que surgirá entre as características da virtude intelectual em questão e o jurídico podem levar a falsificar este último.

A sistematização excessiva do direito é efeito, ao menos em parte, do afã de o jurídico tornarse ciência (WIEACKER, 1980, p. 527). A organização das disposições legais, das decisões judiciais e das análises doutrinas é algo desejável; no entanto, pode ser exagerada, fazendo com que o sistema se sobreponha à realidade da vida.

Ora, é preciso recordar que as soluções do legislador, dos tribunais e dos juristas sempre podem ser aperfeiçoadas, e que estamos nos dedicando a uma arte meticulosa, complexa. E que também é fundamental para o bom funcionamento da sociedade e o desenvolvimento das vidas dos indivíduos. Saber classificar o direito é pouco, mas essencial para que demos o primeiro passo em seu conhecimento.

Um autor clássico como Aristóteles tem muito a nos ajudar, como esperamos ter ficado provado no decorrer deste artigo. Não se pode menosprezar alguém que influiu diretamente no modo de pensar dos juristas romanos e medievais, e que segue tendo relevância nos dias de hoje. Antes, será um autor que nos conduzirá a soluções mais satisfatórias do que algumas a que, às vezes por inércia ou falta de reflexão, antes nos apegávamos. 


\section{REFERÊNCIAS}

ABBÀ, Giuseppe. Felicità, vita buona e virtù: saggio di filosofia morale. 2. ed. Roma: LAS, 1995. $358 \mathrm{p}$.

ABBÀ, Giuseppe. Lex et virtus: studi sull'evoluzione della dottrina morale di San Tommaso d’Aquino. Roma: Fontana di Trevi Edizioni, 2010. 296 p.

ARISTÓTELES. Aristoteles graece: ex recensione Immanueles Bekkeri. Berolini: Academia Regia Borussica, 1831. volumen alterum. 676 p.

ARISTÓTELES. Metafísica: ensaio introdutório. Texto grego com tradução e comentário de Giovanni Reale. Tradução Marcelo Perine. São Paulo: Loyola, 2002. 696 p.

ARISTÓTELES. The complete works of Aristotle: The revised Oxford translation. Edited by BARNES, Jonathan. Princeton: Princeton University Press, 1991. t. 1: 1757 p.; t. 2: 1644 p.

AUBENQUE, Pierre. La prudencia en Aristóteles. Tradução María José Torres Gómez-Pallete. Barcelona: Crítica, 1999. 250 p.

BARZOTTO, Luis Fernando. O positivismo jurídico contemporâneo: uma introdução a Kelsen, Ross e Hart. São Leopoldo: Unisino, 1999. 152 p.

BERTI, Enrico. Aristóteles no século XX. Tradução Dion Davi Macedo. São Paulo: Loyola, 1997. $334 \mathrm{p}$.

BERTI, Enrico. Novos estudos aristotélicos III: filosofia prática. Tradução Élcio de Gusmão Verçosa Filho. São Paulo: Loyola, 2014. 334 p.

BOBBIO, Norberto. Teoria generale del diritto. Torino: Giappichelli, 1993. 298 p.

BROADIE, Sarah. Ethics with Aristotle. Oxford: Oxford University Press, 1991. 462 p.

CARBONNIER, Jean. Flexible droit: pour une sociologie du droit sans rigueur. 10. ed. Paris: LGDJ, 2001. 494 p.

DEVITT, Michael. Realism/Anti-realism. In: PSILLOS, Stathis; CURD, Martin (Ed.). The Routledge companion to philosophy of science. London: Routledge, 2008. p. 224-235.

FERRAZ JÚNIOR, Tércio Sampaio. Introdução ao estudo do direito: técnica, decisão, dominação. 8. ed. São Paulo: Atlas, 2015. 340 p.

FESER, Edward. Philosophy of mind: A beginner’s guide. Oxford: Oneworld, 2006. 268 p.

FINNIS, John. Philosophy of law: Collected essays, v. 4. Oxford: Oxford Press, 2011. 510 p.

GILSON, Etienne. The unity of philosophical experience. New York: Charles Scribner's Sons, 1950. $334 \mathrm{p}$. 
HEIDEGGER, Martin. The question concerning technology and other essays. Tradução e introdução William Lovitt. New York: Garland Publishing, 1977. 184 p.

HOLMES JR., Oliver Wendell. The path of law. Auckland: The floating press, 2009. 41 p.

IRWIN, Terence. Aristotle’s first principles. Oxford: Oxford University Press, 1988. 702 p.

KAUFMANN, Arthur. A problemática da filosofia do direito ao longo da história. In: KAUFMANN, Arthur; HASSEMER, Winfried (Org.). Introdução à filosofia do direito e à teoria do direito contemporâneas. Tradução Marcos Keel. Lisboa: Calouste Gulbenkian, 2002. p. 57-208.

KELSEN, Hans. Teoria pura do direito. Tradução João Baptista Machado. 8. ed. São Paulo: WMF Martins Fontes, 2009. 428 p.

KINCAID, Harold. Social sciences. In: PSILLOS, Stathis; CURD, Martin (Ed.). The Routledge companion to philosophy of science. London: Routledge, 2008. p. 594-604.

KIRSTE, Stephan. Introdução à filosofia do direito. Tradução Paula Nasser. Belo Horizonte: Fórum, 2013. 200 p.

LARENZ, Karl. Metodologia da ciência do direito. Tradução José Lamego. 3. ed. Lisboa: Calouste Gulbenkian, 1997. 728 p.

LEITER, Brian. American legal realism. In: GOLDING, Martin P.; EDMUNDSON, William A. The Blackwell guide to the philosophy of law and legal theory. Oxford: Blackwell, 2005. p. 50-66.

MACINTYRE, Alasdair. After virtue: A study in moral theory. 3. ed. Notre Dame: University of Notre Dame Press, 2007. 288 p.

NEUMANN, Ulfrid. Teoria científica da ciência do direito. In: KAUFMANN, Arthur; HASSEMER, Winfried (Org.). Introdução à filosofia do direito e à teoria do direito contemporâneas. Tradução Marcos Keel. Lisboa: Calouste Gulbenkian, 2002. p. 463-480.

NIETZSCHE, Friedrich. The gay science. Tradução Walter Kaufmann. New York: Vintage Books, 1974. $398 \mathrm{p}$.

ORREGO SÁNCHEZ, Cristóbal. Analítica del derecho justo: la crisis del positivismo jurídico y la crítica del derecho natural. México: UNAM, 2005. 218 p.

OWENS, Joseph. Aristotle: The collected papers of Joseph Owens. Albany: State University of New York Press, 1981. 264 p.

PIEPER, Joseph. Leisure: The basis of culture. Tradução Alexander Dru. Introdução de T. S. Eliot. New York: New American Library, 1963. 128 p.

PIEPER, Joseph. The four cardinal virtues. Notre Dame: University of Notre Dame Press, 1966. $234 \mathrm{p}$. 
PONTES DE MIRANDA, Francisco Cavalcanti. Tratado de direito privado. Atualizado por Otávio Luiz Rodrigues Júnior, Tilman Quarch, Jefferson Carús Guedes. São Paulo: Revista dos Tribunais, 2012. t. 6. 830 p.

PORTIDES, Demetris. Models. In: PSILLOS, Stathis; CURD, Martin (Ed.). The Routledge companion to philosophy of science. London: Routledge, 2008. p. 385-395.

POSTEMA, Gerald J. Legal philosophy in the twentieth century: The common law world. New York: Springer, 2011. 618 p.

REALE, Miguel. Filosofia do direito. 19. ed. São Paulo: Saraiva, 2002. 750 p.

ROTHBARD, Murray. Making economic sense. Auburn: Ludwig von Mises Institute, 1995. 380 p.

SCHULZ, Fritz. History of Roman legal science. Oxford: Oxford University Press, 1946. 360 p.

SCHULZ, Fritz. Principles of Roman law. Oxford: Oxford University Press, 1936. 270 p.

SCHUMPETER, Joseph A. History of economic analysis. London: Routledge, 2006. 1284 p.

SHECAIRA, Fábio Perin. Legal Scholarship and the subject matter of jurisprudence. Archiv für Rechts- und Sozialphilosophie, Stuttgart, v. 101, n. 3, p. 411-427, 2015.

STRAUSS, Leo. Natural right and history. Chicago: The University of Chicago Press, 1992. 326 p.

TOMÁS DE AQUINO. Suma teológica. São Paulo: Loyola, 2001-2006. 9 v.

WIEACKER, Franz. História do direito privado moderno. Tradução A. M. Botelho Hespanha. Lisboa: Calouste Gulbenkian, 1980. 770 p.

Renato José de Moraes Professor substituto na Faculdade de Direito da UFRJ, no Departamento de Teoria do Direito. Possui graduação em Direito pela Pontifícia Universidade Católica de Campinas (1993), mestrado em Direito Civil pela Universidade de São Paulo (1999) e doutorado em Filosofia pela UFRJ (2015). E-mail: renatojmoraes@gmail.com

O autor agradece os comentários e sugestões dos professores Fábio Perin Shecaira (UFRJ) e Daniel Nunes Pêcego (Uerj), e dos revisores anônimos da Revista da Faculdade de Direito UFPR, a respeito de versões anteriores deste artigo. 